\title{
Electrocardiographic abnormalities in amateur male marathon runners
}

\author{
Anna M. Kaleta ${ }^{1, A-D, F}$, Ewa Lewicka ${ }^{1, A-C, E, F}$, Alicja Dąbrowska-Kugacka ${ }^{1, A-C, E, F}$, Zuzanna Lewicka-Potocka ${ }^{1, A-C}$, Elżbieta Wabich ${ }^{1, A-C}$, \\ Anna Szerszyńska ${ }^{2, B, C}$, Julia Dyda ${ }^{2, B, C}$, Jakub Sobolewski ${ }^{2, B, C}$, Jakub Koenner ${ }^{2, B, C}$, Grzegorz Raczak ${ }^{1, A, E, F}$ \\ ${ }^{1}$ Department of Cardiology and Electrotherapy, Medical University of Gdańsk, Poland \\ ${ }^{2}$ Students' Cardiology Scientific Association, Department of Cardiology, Medical University of Gdańsk, Poland \\ $A$ - research concept and design; $B$ - collection and/or assembly of data; $C$ - data analysis and interpretation; \\ $\mathrm{D}$ - writing the article; $\mathrm{E}$ - critical revision of the article; $\mathrm{F}$ - final approval of the article
}

\author{
Address for correspondence \\ Anna M. Kaleta \\ E-mail:ania.m.kaleta@gmail.com \\ Funding sources \\ None declared \\ Conflict of interest \\ None declared
}

Received on November 21, 2016

Reviewed on April 19, 2017

Accepted on May 11, 2017

\begin{abstract}
Background. Sports activity has become extremely popular among amateurs. Electrocardiography is a useful tool in screening for cardiac pathologies in athletes; however, there is little data on electrocardiographic abnormalities in the group of amateur athletes.
\end{abstract}

Objectives. The aim of this study was to analyze the abnormalities in resting and exercise electrocardiograms (ECGs) in a group of amateur athletes, and try to determine whether the criteria applied for the general population or for athletes' ECGs should be implemented in this group.

Material and methods. In 40 amateur male marathon runners, 3 consecutive 12-lead ECGs were performed: $2-3$ weeks before (stage 1), just after the run (stage 2) and 2-3 weeks after the marathon (stage 3). Resting (stage 1) and exercise (stage 2) ECGs were analyzed following the refined criteria for the assessment of athlete's ECG (changes classified as training-related, borderline or training-unrelated).

Results. In resting ECGs, at least 1 abnormality was found in $92.5 \%$ of the subjects and the most common was sinus bradycardia (62.5\%). In post-exercise ECGs, at least 1 abnormality was present in $77.5 \%$ of the subjects and the most common was right atrium enlargement (RAE) (42.5\%). Training-related ECG variants were more frequent at rest ( $82.5 \%$ vs $42.5 \% ; p=0.0008)$, while borderline variants - after the run ( $22.5 \%$ vs $57.5 \%$; $p=0.0004)$. Training-unrelated abnormalities were found in $15 \%$ and $10 \%$ of the subjects, respectively ( $p$-value - nonsignificant), and the most common was T-wave inversion.

Conclusions. Even if the refined criteria rather than the criteria used for normal sedentary population were applied, the vast majority of amateur runners showed at least 1 abnormality in resting ECGs, which were mainly training-related variants. However, at rest, in 15\% of the subjects, pathologic training-unrelated abnormalities were found. The most frequent post-exercise abnormality was right atrial enlargement. General electrocardiographic screening in amateur athletes should be taken into consideration.

Key words: electrocardiography, athlete's heart, sports cardiology, refined criteria, amateur runners

DOI

10.17219/acem/73700

\section{Copyright}

Copyright by Author(s)

This is an article distributed under the terms of the

Creative Commons Attribution Non-Commercial License

(http://creativecommons.org/licenses/by-nc-nd/4.0/) 


\section{Introduction}

Electrocardiography is a generally accepted and effective tool in athletes' screening for cardiac pathologies. ${ }^{1,2}$ Electrocardiographic abnormalities are common among athletes and they most often reflect physiological structural adaptive changes, a phenomenon known as 'athlete's heart'. Thus, in the assessment of athlete's resting electrocardiogram (ECG), specific criteria have to be used. Moreover, the so called 'refined criteria' appear to be the most specific and sensitive in screening for cardiac pathologies (most often hypertrophic cardiomyopathy) in both white and black elite athlete populations. ${ }^{3}$ Nowadays, apart from professional athletes, there is an increasingly growing number of amateurs who participate in numerous competitive sports events, even as strenuous as a marathon run. That is why we found it interesting to examine the impact of intensive exercise such as a marathon run on the electrocardiographic findings in this population. As participating in a marathon requires regular physical preparation from people who are amateurs, we decided to apply the same criteria for their electrocardiographic findings assessment which are used in elite athletes. ${ }^{3}$

On this ground, a question arises whether electrocardiographic screening would be reasonable also among amateur athletes.

\section{Material and methods}

\section{Data collection}

This was a prospective and observational study performed in a group of amateur runners who participated in the $2^{\text {nd }}$ PZU Gdańsk Marathon. The study was divided into 3 stages: the $1^{\text {st }}$ measurement was carried out 2-3 weeks before the marathon; the $2^{\text {nd }}$ - on the day of the marathon on the finish line; and the $3^{\text {rd }}$ stage $-2-3$ weeks after the marathon. The $1^{\text {st }}$ and $3^{\text {rd }}$ examination took place in the Department of Cardiology and Electrotherapy of the Medical University of Gdańsk, Poland. At each stage, a standard 12-lead ECG was recorded in the supine position, using a digital electrocardiograph (Mortara, ELI 250c with baseline filter, $\mathrm{AC}$ interference filter $50 / 60 \mathrm{~Hz}$ and low-pass $40 \mathrm{~Hz}$ filter; Mortara Instrument, Milwaukee, USA) at a paper speed of $25 \mathrm{~mm} / \mathrm{s}$. At stage 1 and 3 it was recorded after $3 \mathrm{~min}$ of rest, during quiet respiration, and at stage 2 - just after finishing the marathon, on the finish line. The interpretation of the ECGs followed the criteria as listed below. contractions.
The study protocol was approved by the Bioethics Committee of the Medical University of Gdańsk, Poland (No. NKBBN 104/2016) and a written consent was obtained from each participant.

\section{Study group}

The study group consisted of 40 male amateur marathon runners with no history of diagnosed chronic illnesses. Information about personal health and the intensity of training defined in hours per week was obtained by anamnesis.

\section{ECG measurements}

The following criteria for the evaluation of ECG abnormalities were used. Sinus bradycardia was defined as a sinus rhythm below $60 \mathrm{bpm}$. The P-waves were analyzed in the context of left atrium enlargement (LAE) and right atrium enlargement (RAE). LAE was defined as the P-wave duration $>120 \mathrm{~ms}$ in lead I or II, or a negative portion of the P-wave of $\geq 0.1 \mathrm{mV}$ in depth and $\geq 40 \mathrm{~ms}$ in duration in lead $V_{1}$. RAE was defined as the P-wave amplitude $\geq 0.25 \mathrm{mV}$ in lead II, III or aVF. Figure 1 illustrates the measurement of P-waves in the context of LAE/RAE. Left ventricular hypertrophy $(\mathrm{LVH})$ was defined when at least 1 of the following criteria was fulfilled: Sokolow-Lyon criteria or Cornell criteria, R-wave in lead aVL $>1.1 \mathrm{mV}$, or R-wave in lead I and S-wave in lead III $>2.5 \mathrm{mV}$, given there were no intraventricular conduction delays. Right ventricular hypertrophy (RVH) was defined when at least 1 of the following criteria was fulfilled: R-wave in lead aVR $\geq 0.5 \mathrm{mV}$, or R-wave in lead $\mathrm{V}_{1} \geq 0.7 \mathrm{mV}$, or R-wave in lead $\mathrm{V}_{1}$ and $\mathrm{S}$-wave in lead $\mathrm{V}_{5}$ or $\mathrm{V}_{6}>1.05 \mathrm{mV}$. T-wave inversion (TWI) was defined as negative T-waves $>1 \mathrm{~mm}$ in depth in $\geq 2$ leads: $V_{2}-V_{6}$, II and aVF, or I and aVL (excludes leads III, aVR and $\mathrm{V}_{1}$ ). QT intervals were measured manually. QT dispersion was calculated as the difference between

Table 1. Classification of variants of electrocardiographic abnormalities

\begin{tabular}{|c|c|c|}
\hline Training-related & Borderline & Training-unrelated \\
\hline $\begin{array}{l}\text { Sinus bradycardia } \\
1^{\text {st }} \text { degree AVB (PR }>200 \text { ms) } \\
n R B B B \\
\text { ER } \\
\text { Isolated QRS voltage criteria for LVH }\end{array}$ & $\begin{array}{l}\text { LAE } \\
\text { RAE } \\
\text { Left QRS axis deviation } \\
\text { Right QRS axis deviation } \\
\text { RVH }\end{array}$ & $\begin{array}{l}\text { ST segment depression } \\
\text { Pathological Q-waves } \\
\text { Ventricular preexcitation } \\
\text { TWI beyond } V_{1} \\
\text { LBBB } \\
\text { RBBB } \\
\text { QTC } \geq 470 \text { ms } \\
\text { QTc }<320 \text { ms } \\
\text { Brugada-like ER } \\
\text { Atrial arrhythmias } \\
\text { Ventricular arrhythmias } \\
\geq 2 \text { PVCs/10s tracing } \\
\geq 2 \text { borderline variants }\end{array}$ \\
\hline
\end{tabular}

AVB - atrioventricular block; nRBBB - non-complete right bundle branch block; ER - early repolarization; LVH - left ventricular hypertrophy; LAE - left atrial enlargement; RAE - right atrial enlargement; RVH - right ventricular hypertrophy; TWI - T-wave inversion; LBBB - left bundle branch block; RBBB - right bundle branch block; PVCs - premature ventricular 
the longest $\left(\mathrm{QT}_{\max }\right)$ and the shortest $\left(\mathrm{QT}_{\min }\right) \mathrm{QT}$ interval in the 12-lead ECG. QTc values for heart rates between $60 \mathrm{bpm}$ and $110 \mathrm{bpm}$ were calculated using Bazett's formula. Framingham formula was used for heart rates lower than $60 \mathrm{bpm}$ and higher than $110 \mathrm{bpm}$. Prolonged QT was defined as QTc $\geq 470 \mathrm{~ms}$ in males, following the refined criteria. ${ }^{3}$ Short QT interval was defined as QTc $<320 \mathrm{~ms}$, following the Seattle criteria. ${ }^{4}$ Brugada-like early repolarization (ER) pattern was defined as 'upsloping' ST-segment elevation with $\mathrm{ST}_{\mathrm{J}} / \mathrm{ST}_{80}$ ratio $<1\left(\mathrm{ST}_{\mathrm{J}}=\right.$ elevation of ST-segment measured at J point; $\mathrm{ST}_{80}=$ elevation of ST-segment measured $80 \mathrm{~ms}$ from J point). ${ }^{5}$

The ECG findings were divided into 3 groups, following the refined criteria for the interpretation of athlete's ECG, namely: training-related, borderline and trainingunrelated (pathological) (Table 1$){ }^{3}$ We used the refined criteria, which are the latest recommendations on this topic. If at least 2 borderline variants were found on the ECG, it was categorized as 'training-unrelated variant', but it did not apply if the left and right atrial enlargement came together.

All ECGs were interpreted independently by 2 investigators. Disagreements were resolved by the $3^{\text {rd }}$ investigator.

Each participant presenting with any training-unrelated variant underwent further detailed investigations (however, their results are not the subject of this particular study).

\section{Statistical analysis}

Data is presented as mean values with standard deviation (SD), participant numbers and percentages. Normally distributed variables were compared using the Student's t test, and the Mann-Whitney U test was used to compare independent non-normally distributed variables. Differences between categorical variables were assessed using the $X^{2}$ test. Statistical analysis was performed using the Stata software v. 12.1 (StataCorp LLC, College Station, USA). A p-value $<0.05$ was considered statistically significant.

\section{Results}

\section{Study group}

A total of 40 Caucasian male amateur runners aged between 22 and 55 years were enrolled in the study. The intensity of training was expressed as a number of hours of running a week and by the number of kilometers run a week. Table 2 shows demographic data and the intensity of training in the studied group.

There were no significant differences in the ECG findings between stages 1 and 3, and for comparison with exercise ECG (stage 2) we used the data collected at stage 1. Results of the measurements of electrocardiographic parameters are shown in Table 3.
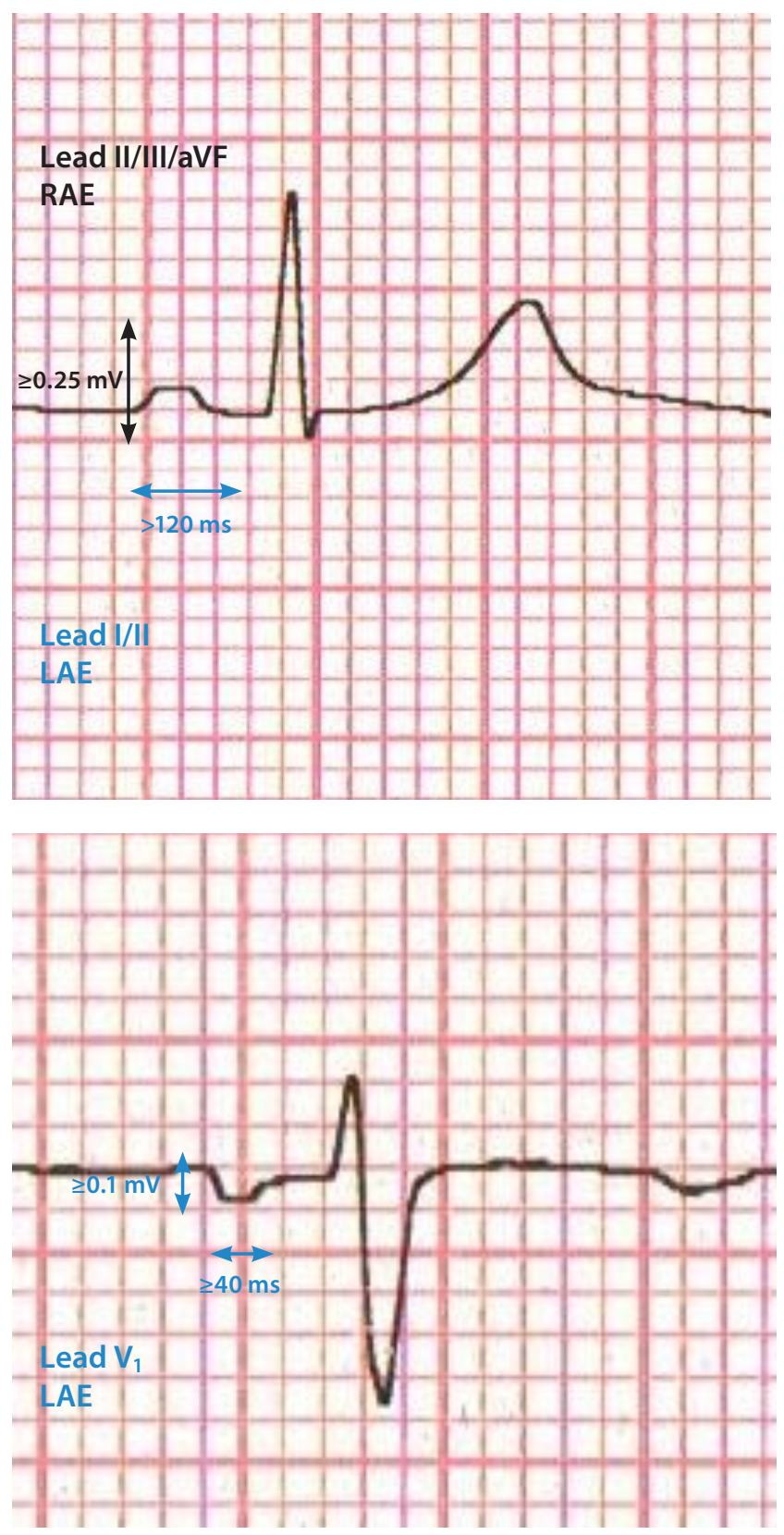

Fig. 1. Principles of measurement of P-waves in the context of $L A E / R A E$ (voltage: $10 \mathrm{~mm}=1 \mathrm{mV}$; paper speed: $25 \mathrm{~mm} / \mathrm{s}$ )

LAE - left atrial enlargement; RAE - right atrial enlargement.

Table 2. Demographic data and intensity of training in the studied group of amateur marathon runners

\begin{tabular}{|c|c|}
\hline $\begin{array}{c}\text { Demographics } \\
\text { and intensity of training }\end{array}$ & Amateur runners $(n=40)$ \\
\hline Age [years] & $39 \pm 8$ \\
\hline Gender & 40 males (100\%) \\
\hline BMI $\left[\mathrm{kg} / \mathrm{m}^{2}\right]$ & $25 \pm 2$ \\
\hline Ethnicity & 40 Caucasian (100\%) \\
\hline $\begin{array}{l}\text { Training intensity: } \\
\text { hours of running/week } \\
\text { kilometers run/week }\end{array}$ & $\begin{array}{c}6.2 \pm 2.3 \\
54.5 \pm 18.6\end{array}$ \\
\hline
\end{tabular}

$\mathrm{BMI}$ - body mass index. 
Table 3. Electrocardiographic measurements at rest (stage 1) and after the marathon run (stage 2) in the studied group

\begin{tabular}{|l|r|r|c|}
\multicolumn{1}{|c|}{ Parameter } & Stage 1 & Stage 2 & p-value \\
\hline Heart rate [bpm] & $57 \pm 11$ & $94 \pm 10$ & $<0.0001$ \\
\hline QRS [ms] & $96 \pm 12$ & $95 \pm 10$ & 0.6 \\
\hline PQ interval [ms] & $166 \pm 23$ & $160 \pm 19$ & 0.2 \\
\hline P-wave duration [ms] & $103 \pm 14$ & $105 \pm 13$ & 0.4 \\
\hline P-wave amplitude [mV] & $0.1 \pm 0.04$ & $0.2 \pm 0.1$ & $<0.0001$ \\
\hline QT interval [ms] & $417 \pm 31$ & $346 \pm 23$ & $<0.0001$ \\
\hline QTc [ms] & $430 \pm 23$ & $407 \pm 24$ & $<0.0001$ \\
\hline QT $T_{\min }$ [ms] & $398 \pm 31$ & $331 \pm 24$ & $<0.0001$ \\
\hline QT $T_{\text {max }}$ [ms] & $435 \pm 31$ & $369 \pm 25$ & $<0.0001$ \\
\hline QT dispersion [ms] & $37 \pm 16$ & $37 \pm 14$ & 0.9 \\
\hline
\end{tabular}

stage 1 - examination performed 2-3 weeks before the marathon run; stage 2 - examination on the day of the marathon on the finish line.

\section{ECG measurements}

The mean heart rate at rest ( $57 \pm 11 \mathrm{bpm})$ was significantly lower than the mean heart rate after the marathon run (94 $\pm 10 \mathrm{bpm})$. There were no significant differences between the QRS and PQ interval duration. The duration of the P-wave showed no significant differences, but its amplitude was significantly higher after the run $(0.1 \pm 0.04 \mathrm{mV}$ vs $0.2 \pm 0.1 \mathrm{mV}$; $\mathrm{p}<0.0001$ ).

We observed significant differences regarding the duration of QT interval. After the marathon run, the QT and QTc interval, as well as $\mathrm{QT}_{\min }$ and $\mathrm{QT} \mathrm{T}_{\max }$, were significantly shorter compared to resting ECGs. However, there was no significant difference between QT dispersion at stage 1 and stage 2 (37 $\pm 16 \mathrm{~ms}$ and $37 \pm 14 \mathrm{~ms}$, respectively).

\section{Classification of ECG variants}

At least 1 electrocardiographic abnormality was found in 37 subjects at rest (92.5\%), and in 31 - after the marathon run (77.5\%). Table 4 shows the results of the ECG findings classified as training-related, borderline or trainingunrelated (pathological).

In ECGs performed at rest, 25 participants (62.5\%) presented sinus bradycardia and the lowest basic heart rate was $41 \mathrm{bpm}$, seen in 2 subjects. Sinus bradycardia was the most common training-related finding, followed by LVH by voltage criteria in 12 (30\%) subjects and early repolarisation in 11 (20.4\%). First degree atrioventricular block (AVB) was found in 4 (10\%) participants, and noncomplete right bundle branch block (nRBBB) in 2 (5\%).

After the marathon run, neither sinus bradycardia nor $1^{\text {st }}$ degree AVB were observed. There were no significant differences regarding the occurrence of $n R B B B, L V H$ or ER compared to resting ECGs.

The total number of training-related variants was significantly higher at stage 1 compared to stage 2 (54 vs 23;

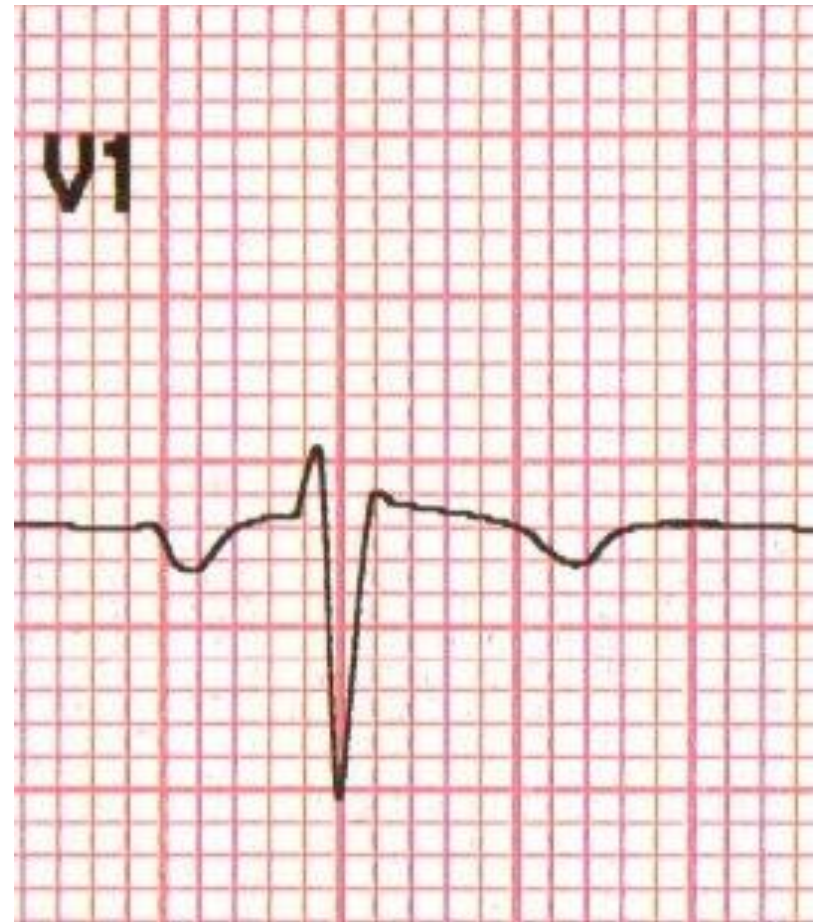

Fig. 2. Stage 1. LAE. Negative portion of P-wave of $0.12 \mathrm{mV}$ in depth and $70 \mathrm{~ms}$ in duration in lead $V_{1}$ (voltage: $10 \mathrm{~mm}=1 \mathrm{mV}$; paper speed: $25 \mathrm{~mm} / \mathrm{s}$ )

LAE - left atrial enlargement.

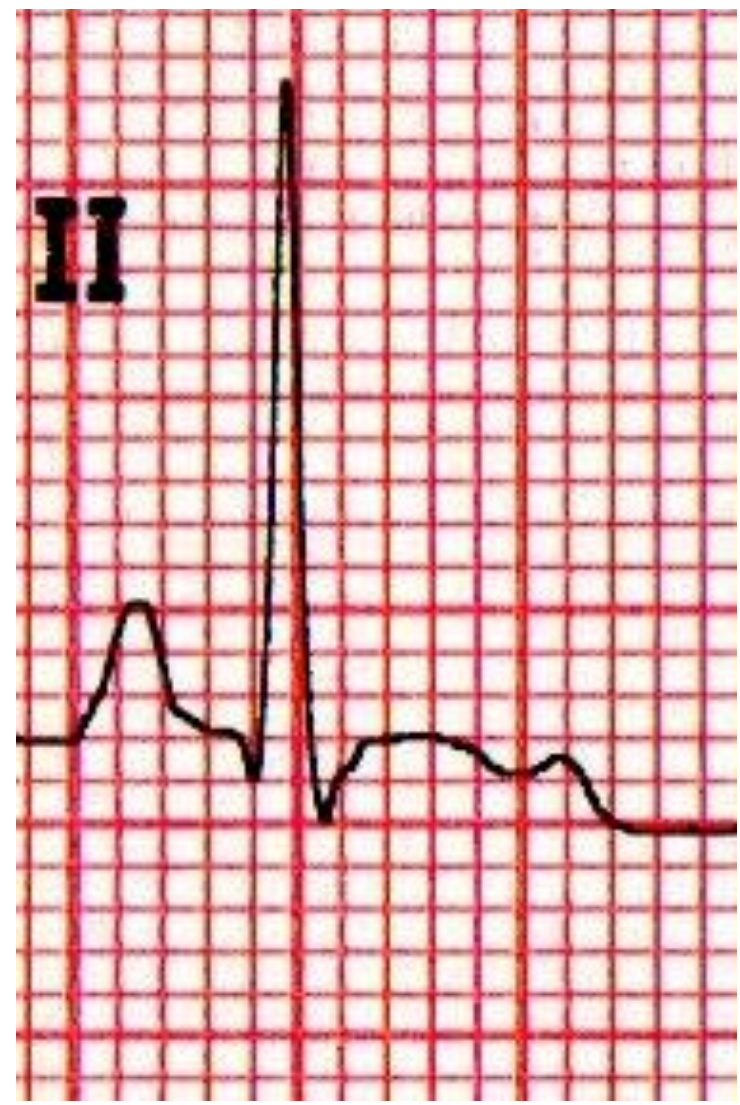

Fig. 3. Stage 2. RAE. P-wave amplitude of $0.3 \mathrm{mV}$ in lead II (voltage: $10 \mathrm{~mm}=1 \mathrm{mV}$; paper speed: $25 \mathrm{~mm} / \mathrm{s}$ )

RAE - right atrial enlargement. 
$\mathrm{p}=0.0004$ ), mainly due to frequent sinus bradycardia, which was a common finding in resting ECGs.

When analyzing borderline ECG variants, all of them were isolated and none of the participants had more than 1 borderline ECG variant. The most common finding was LAE. The example of LAE in 1 of the participants at stage 1 is shown in Fig. 2.

The number of ECGs meeting the criteria for LAE was higher after the marathon run, which was borderline significant ( 15 vs 8 at rest; $\mathrm{p}=0.05$ ). What is more, we found that the incidence of right atrium enlargement was significantly higher at stage 2 ( 0 vs 17; p < 0.0001). Figure 3 shows the example of RAE in one of the participants at stage 2 .

The total number of borderline variants was significantly higher at stage 2 ( 35 vs 9; $\mathrm{p}<0.0001$ ), due to common RAE and LAE findings after the marathon run.

Training-unrelated ECG variants were the least common findings in the studied group and TWI dominated (Table 4). In resting ECGs, 5 participants presented abnormal TWI compared to 2 participants after the run, who also showed TWI at rest. Figure 4 shows TWI in one of the participants at stage 1 . Changes in inferior leads occurred slightly more often than in lateral leads. There were no TWI in anterior leads. In 1 case, TWI in both lateral and inferior leads was observed after the run (Table 5, Fig. 5). QTc interval prolongation was present in 1 case at stage 1 and in 2 cases at stage 2 (Table 4), and the longest QTc in our group was $470 \mathrm{~ms}$.

Training-related variants were more common at rest ( $p=0.0008)$; borderline variants were more frequently observed after exercise $(\mathrm{p}=0.0004)$, while there was no difference in the rate of training-unrelated changes between stage 1 and 2 (Table 6). In some cases, participants presented abnormalities belonging to more than 1 variant. At stage 1, 4 subjects had both training-related and borderline variants, 3 had both training-related and unrelated variants, while 2 had training-related, borderline and training-un related variants. At stage 2, 2 subjects had training-related, borderline and training-unrelated variants and 8 subjects had both training-related and borderline variants.

\section{Discussion}

This pilot study is the first one performed among Polish amateur marathon runners that assesses and compares the ECG changes in such a study population. We noticed that even in a relatively small study group of healthy male amateur runners, various ECG abnormalities can be found. If the criteria used for the general population had been applied, then the abnormalities in resting ECGs would have been observed in $92.5 \%$ of subjects. If classified as trainingrelated, according to the refined criteria for elite athletes, these findings would also have been found in the vast
Table 4. Variants of electrocardiographic abnormalities at rest (stage 1) and after the marathon run (stage 2) in the studied group of amateur marathon runners

\begin{tabular}{|c|c|c|c|}
\hline Parameter & $\begin{array}{l}\text { Stage } 1 \\
(n=40)\end{array}$ & $\begin{array}{l}\text { Stage } 2 \\
(n=40)\end{array}$ & p-value \\
\hline \multicolumn{4}{|c|}{ Training-related variants } \\
\hline Sinus bradycardia & $25(62.5 \%)$ & $0(0 \%)$ & $<0.0001$ \\
\hline $1^{\text {st }}$ degree AVB & $4(10 \%)$ & $0(0 \%)$ & 0.05 \\
\hline$n R B B B$ & $2(5 \%)$ & $2(5 \%)$ & 0.9 \\
\hline $\begin{array}{l}\text { LVH (isolated voltage } \\
\text { criteria) }\end{array}$ & $12(30 \%)$ & $14(35 \%)$ & 0.5 \\
\hline ER & $11(20.4 \%)$ & $7(17.5 \%)$ & 0.4 \\
\hline Total & $54(78.3 \%)^{*}$ & $23(37.1 \%)^{\#}$ & 0.0004 \\
\hline \multicolumn{4}{|c|}{ Borderline variants } \\
\hline Left QRS axis deviation & $0(0 \%)$ & $0(0 \%)$ & na \\
\hline Right QRS axis deviation & $0(0 \%)$ & $1(2.5 \%)$ & 0.3 \\
\hline LAE & $8(20 \%)$ & $15(37.5 \%)$ & 0.05 \\
\hline RAE & $0(0 \%)$ & $17(42.5 \%)$ & $<0.0001$ \\
\hline $\mathrm{RVH}$ & $1(2.5 \%)$ & $2(5 \%)$ & 0.5 \\
\hline Total & $9(13 \%)^{*}$ & $35(56.5 \%)^{\#}$ & $<0.0001$ \\
\hline \multicolumn{4}{|c|}{ Training-unrelated variants } \\
\hline ST segment depression & $0(0 \%)$ & $0(0 \%)$ & na \\
\hline Pathological Q-waves & $0(0 \%)$ & $0(0 \%)$ & na \\
\hline Ventricular preexcitation & $0(0 \%)$ & $0(0 \%)$ & na \\
\hline TWI beyond $V_{1}$ & $5(12.5 \%)$ & $2(5 \%)$ & 0.3 \\
\hline Brugada-like ER & $0(0 \%)$ & $0(0 \%)$ & na \\
\hline Atrial arrhythmias & $0(0 \%)$ & $0(0 \%)$ & na \\
\hline Ventricular arrhythmias & $0(0 \%)$ & $0(0 \%)$ & na \\
\hline$\geq 2$ PVCs/10s tracing & $0(0 \%)$ & $0(0 \%)$ & na \\
\hline $\mathrm{QTC} \geq 470 \mathrm{~ms}$ & $1(2.5 \%)$ & $2(5 \%)$ & 0.5 \\
\hline QTc $<320 \mathrm{~ms}$ & $0(0 \%)$ & $0(0 \%)$ & na \\
\hline LBBB & $0(0 \%)$ & $0(0 \%)$ & na \\
\hline RBBB & $0(0 \%)$ & $0(0 \%)$ & na \\
\hline Total & $6(8.7 \%)^{*}$ & $4(6.5 \%)^{\#}$ & 0.6 \\
\hline
\end{tabular}

ECG - electrocardiography; AVB - atrioventricular block; nRBBB - noncomplete right bundle branch block; LVH - left ventricular hypertrophy; $E R$ - early repolarization; LAE - left atrial enlargement; RAE - right atrial enlargement; RVH - right ventricular hypertrophy; TWI - T-wave inversion; PVCs - premature ventricular contractions; LBBB - left bundle branch block; RBBB - right bundle branch block; na - not applicable; * percentage of all electrocardiographic abnormalities at stage $1(n=69)$; \# percentage of all electrocardiographic abnormalities found at stage 2 $(n=62)$.

Table 5. T-wave inversion and its localisation in the ECGs at rest (stage 1) and after the marathon run (stage 2 ) in the studied group

\begin{tabular}{|l|c|c|c|}
\multicolumn{1}{|c|}{ Leads } & Stage 1 & Stage 2 & p-value \\
\hline Normal isolated anterior $\left(\mathrm{V}_{1}\right)$ & $24(60 \%)$ & $3(7.5 \%)$ & $<0.0001$ \\
\hline Normal isolated inferior $(\mathrm{III})$ & $18(45 \%)$ & $16(40 \%)$ & 0.9 \\
\hline Abnormal anterior $\left(\mathrm{V}_{2}-\mathrm{V}_{4}\right)$ & $0(0 \%)$ & $0(0 \%)$ & na \\
\hline Lateral $\left(\mathrm{I}, \mathrm{aVL}, \mathrm{V}_{5}, \mathrm{~V}_{6}\right)$ & $2(5 \%)$ & $1^{*}(2.5 \%)$ & 0.6 \\
\hline Inferior $(\mathrm{II}, \mathrm{aVF})$ & $3(7.5 \%)$ & $2^{*}(5 \%)$ & 0.7 \\
\hline
\end{tabular}

ECGs - electrocardiographs; na - not applicable; * 1 participant at stage 2 had findings in more than 1 location. 

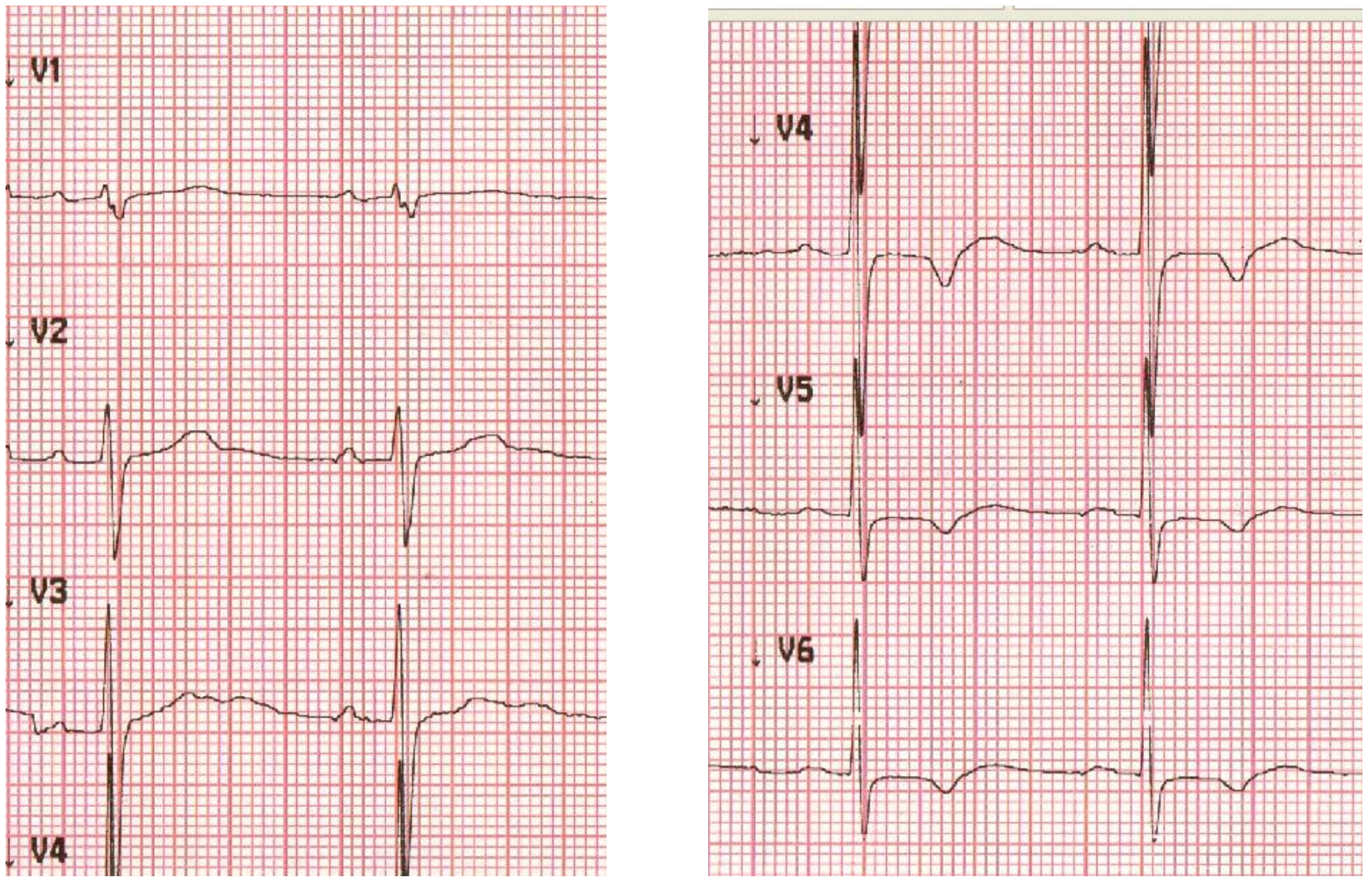

Fig. 4. Stage 1. T-wave inversions in leads V4, V5, V6 (voltage: $10 \mathrm{~mm}=1 \mathrm{mV}$; paper speed: $25 \mathrm{~mm} / \mathrm{s}$ )

majority of the studied group: $82.5 \%{ }^{3}$ Moreover, $15 \%$ of the subjects presented pathological, training-unrelated variants in their resting ECGs. This data shows that amateur athletes should undergo ECG screening, especially if they plan to participate in competitions.

In our group, sinus bradycardia was the most commonly observed ECG finding (62.5\% of the participants). A heart rate below $60 \mathrm{bpm}$ is frequently reported among athletes. A commonly believed reason for resting bradycardia in athletes is an increased vagal tone, but recent studies focus also on another mechanism, namely the ion channel remodeling of the sinus node. ${ }^{6-8}$ There are studies that show the relationship between the autonomic tone variations and atrial fibrillation. Bettomi and Zimmermann indicated that an increased vagal tone may contribute to the development of atrial fibrillation in athletes by shortening and increasing the dispersion of atrial refractory period, and thus creating a re-entry pathway. ${ }^{9}$

Among borderline variants, the most common finding in resting ECGs was LAE (20\% of the participants). The data regarding the relationship of LAE and the occurrence of supraventricular arrhythmias in athletes is conflicting and requires further research. Pelliccia et al. stated that, although LAE and remodeling are common in athletes and subjects undertaking long-time regular physical training, their clinical significance and long-term arrhythmic consequences remain unresolved, based on the average 7-year follow-up period. ${ }^{10}$ On the other hand, it has been shown that accumulated lifetime physical activity and left atrial size are risk factors for lone atrial fibrillation. ${ }^{11}$ Gabrielli et al. investigated the contractile performance, size and deformation of both atria in athletes, and showed that higher contractile performance of the left and right atrium was compensated by working at higher wall stress and changed the wall geometry, which may predispose to the development of atrial arrhythmias. ${ }^{12}$

Left atrium enlargement found in our group may suggest that even in amateur athletes, left atrium undergoes changes that may predispose to the development of atrial fibrillation. Although LAE occurred in a significant percentage of the participants of our study, none of them presented with any supraventricular arrhythmias in their history. Nevertheless, conclusions can be drawn only after a longer follow-up period.

After the marathon, the most frequent finding was RAE, and the most likely reason for this could be an increase in adrenergic tone. As investigated by Bayés de Luna et al., both sympathetic overdrive and hypoxia (in this case exercise-induced hypoxia) can result in the so-called electrocardiographic 'false-positive' RAE. ${ }^{13}$ Nevertheless, right ventricular overload might be taken into consideration as well. A recent study has shown that after a running race, acute exercise dose-dependent impairment in atrial function, but especially of the right atrium, can occur. ${ }^{14}$ 
In our group, $15 \%$ of the subjects presented with pathological training-unrelated variants in their resting ECGs. We found this percentage significant, because every single training-unrelated variant needs to be further investigated, as it may indicate the presence of cardiac pathologies. Pathological TWI was the most prevalent group. Inferior leads TWI came out in 3 subjects (7.5\%), whereas TWI in lateral leads - in 2 subjects (5\%).

Interestingly, in the case of training-related TWI (leads $\mathrm{V}_{1}$, III), the normalization of T-waves was observed after the marathon run. In lead $V_{1}$, the difference between the frequency of TWI at stage 1 and stage 2 was statistically significant $(\mathrm{p}<0.0001)$. The explanation for this finding may be a high adrenergic tone after strenuous exercise. It was shown in patients with hypertrophic cardiomyopathy who presented negative T-waves on the resting ECG that $\mathrm{T}$-waves became less deeper after the treadmill exercise test in all cases. Moreover, the higher the exercise level, the less deeper T-waves were. ${ }^{15}$ Zeppilli et al. investigated the effect of maximal exercise on TWI in top athletes. ${ }^{16}$ In some cases, the exercise-induced normalization of TWI was observed, and the authors considered the neurogenic mechanism of the phenomenon.

Our results show that in the assessment of amateur athletes' ECGs, the criteria for athletes' ECGs, rather than those for the general population, should be used. Many changes that could suggest pathologies in the general population are benign findings in the ECGs of active people practicing sport. In this particular study, we used the refined criteria that are the latest recommendations on this topic. However, a significant percentage of trainingrelated variants suggests that even amateur athletes should undergo ECG screening before participating in competitions.
Table 6. Number of subjects presenting ECG variants at rest (stage 1) and after the marathon run (stage 2)

\begin{tabular}{|l|c|c|c|}
\multirow{2}{*}{\multicolumn{1}{|c|}{ ECG variant }} & \multicolumn{2}{|c|}{$\begin{array}{c}\text { Number of participants, } \\
\mathrm{n}(\%)\end{array}$} & \multirow{2}{*}{ p-value } \\
\cline { 2 - 3 } & stage 1 & stage 2 & \\
\hline Training-related & $33(82.5 \%)$ & $17(42.5 \%)$ & 0.0008 \\
\hline Borderline & $9(22.5 \%)$ & $23(57.5 \%)$ & 0.0004 \\
\hline Training-unrelated & $6(15 \%)$ & $4(10 \%)$ & 0.6 \\
\hline
\end{tabular}

ECG - electrocardiograph.

In the ECGs recorded after the marathon run, statistically significant differences in QT interval duration and frequency of RAE were observed, and we link these findings with the adrenergic activation of the heart after the run. It has to be emphasized that refined criteria (as well as the Seattle criteria) have been used so far only in the interpretation of resting ECGs. Our study is the first one that applies these criteria to ECGs performed soon after exercise. Although in some cases 2 borderline variants came together, i.e., LAE and RAE, we did not categorize them as training-unrelated because of the abovementioned adrenergic activation. The results of our study show that the refined criteria can be used for the interpretation of athletes' ECGs both at rest and after exercise.

\section{Limitations}

The study group was relatively small and involved only white men living in the Pomeranian Voivodeship, Poland. That is why our findings may not be applicable for larger cohorts and for cohorts with ethnic variability. Moreover,
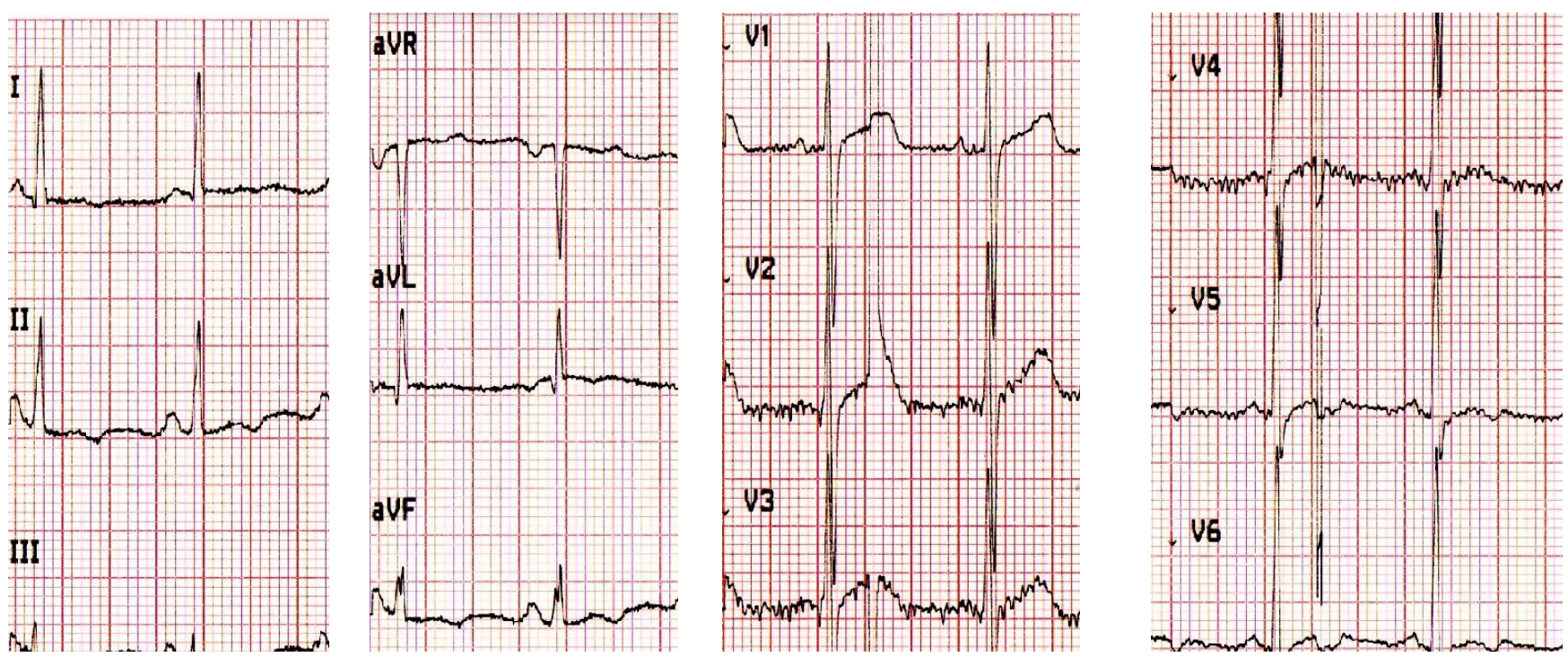

Fig. 5. Stage 2. T-wave inversions in both lateral and inferior leads (ECG performed just after the run on the finish line; voltage: $10 \mathrm{~mm}=1 \mathrm{mV}$; paper speed: $25 \mathrm{~mm} / \mathrm{s})$ 
no women were included in the study; therefore, we cannot draw any conclusions regarding this group of amateur runners. Additionally, there can be doubts whether our subjects could be regarded as 'amateurs'. A single strict definition of an athlete does not actually exist. An athlete is defined as a person who is trained in or good at sports, games or exercises that require physical skill and strength, whereas, according to Italian criteria, an athlete is a person who participates in an organized sports program that requires regular training and competition. ${ }^{17,18}$ Both definitions could be applied also to our study population. However, at this point another question arises, namely where the border between amateur and professional running can actually be set.

\section{Conclusions}

Electrocardiograms of amateur runners include many variants that could be misinterpreted as pathological if general criteria were used for their assessment. That is why criteria applied for athletes' ECGs should be implemented in this group. The most commonly observed abnormalities in both resting and exercise ECGs in our study were trainingrelated changes, which were proved to be benign and require no further examinations. Nevertheless, at rest, in 15\% of the subjects, pathologic training-unrelated abnormalities were found. A high prevalence of abnormalities in our relatively small study group suggests the need of common ECG screening not only among elite athletes, but also in the population of amateurs.

\section{References}

1. Corrado D, Pelliccia A, Heidbuchel $\mathrm{H}$, et al.; Section of Sports Cardiology, European Association of Cardiovascular Prevention and Rehabilitation. Recommendations for interpretation of 12-lead electrocardiogram in the athlete. Eur Heart J. 2010;31:243-259.

2. Drezner JA, Fischbach P, Froelicher V, et al. Normal electrocardiographic findings: Recognizing physiological adaptations in athletes. BrJ Sports Med. 2013;47:125-136.

3. Sheikh N, Papadakis M, Ghani S, et al. Comparison of electrocardiographic criteria for the detection of cardiac abnormalities in elite black and white athletes. Circulation. 2014;129:1637-1649.

4. Drezner JA, Ackerman MJ, Anderson J, et al. Electrocardiographic interpretation in athletes: the Seattle criteria. Br J Sports Med. 2013;47:122-124.

5. Corrado D, Pelliccia A, Antzelevitch C, et al. ST Segment Elevation and Sudden Death in the Athlete. The Brugada Syndrome: From Bench to Bedside. Oxford: Blackwell Futura; 2005.

6. Boyett MR, D'Souza A, Zhang H, Morris GM, Dobrzynski H. Monfredi O. Viewpoint: Is the resting bradycardia in athletes the result of remodeling of the sinoatrial node rather than high vagal tone? J Appl Physiol. 2013;114:1351-1355.

7. Baldesberger S, Bauersfeld U, Candinas R, et al. Sinus node disease and arrhythmias in the long-term follow-up of former professional cyclists. Eur Heart J. 2008;29:71-78.

8. D'Souza A, Bucchi A, Johnsen AB, et al. Exercise training reduces resting heart rate via downregulation of the funny channel HCN4. Nat Commun. 2014;5:3775.

9. Bettomi M, Zimmermann M. Autonomic tone variations before the onset of paroxysmal atrial fibrillation. Circulation. 2002;105:2753-2759.

10. Pelliccia A, Maron BJ, Di Paolo FM, et al. Prevalence and clinical significance of left atrial remodeling in competitive athletes. $J$ Am Coll Cardiol. 2005;46:690-696.
11. Mont L, Tamborero D, Elosua R, et al.; GIRAFA (Grup Integrat de Recerca en Fibrillació Auricular) Investigators. Physical activity, height, and left size are independent risk factors for lone atrial fibrillation in middle-aged healthy individuals. Europace. 2008;10:15-20.

12. Gabrielli L, Bijnens BH, Butakoff $C$, et al. Atrial functional and geometrical remodeling in highly trained male athletes: For better or worse? Eur J Appl Physiol. 2014;114(6):1143-1152.

13. Bayés de Luna A, Boada FX, Casellas A et al. Concealed atrial electrical activity. J Electrocardiol. 1978;11:301-305.

14. Sanz-de la Garza M, Grazioli G, Bijnens BH, et al. Acute, exercise dose-dependent impairment in atrial performance during an endurance race: 2D ultrasound speckle-tracking strain analysis. JACC Cardiovasc Imaging. August 11, 2016 [ahead of print]. doi:10.1016/j. jcmg.2016.03.016

15. Sugishita Y, Yamaguchi T, Ogawa T, et al. Variability of negative T wave in hypertrophic cardiomyopathy: Possible role of betaadrenergic function. Acta Cardiol. 1987;42(2):115-133.

16. Zeppilli P, Pirrami MM, Sassara M, Fenici R. T wave abnormalities in top-ranking athletes: effects of isoproterenol, atropine, and physical exercise. Am Heart J. 1980;100(2):213-222.

17. http://www.merriam-webster.com/dictionary/athlete. Accessed March 20, 2017.

18. Corrado D, Basso C, Rizzoli G, et al. Does sports activity enhance the risk of sudden death in adolescents and young adults? J Am Coll Cardiol. 2003:42:1959-1963. 